\title{
Minimally invasive pancreaticoduodenectomy with venous resection: results of a systematic review
}

\author{
Pietro Addeo', \\ 'Hepato-Pancreato-Biliary Surgery and Liver transplantation, Pôle des Pathologies Digestives, Hépatiques et de la Transplantation, \\ Hôpital de Hautepierre-Hôpitaux Universitaires de Strasbourg, Strasbourg 67098, France. \\ ${ }^{2}$ Images team, ICube, Université de Strasbourg, CNRS UMR 7357, IIlkirch 67400, France.
}

Correspondence to: Dr. Pietro Addeo, Hepato-Pancreato-Biliary Surgery and Liver transplantation, Pôle des Pathologies Digestives, Hépatiques et de la Transplantation, Hôpital de Hautepierre-Hôpitaux Universitaires de Strasbourg, Avenue Molière, Université de Strasbourg 1, Strasbourg 67098, France. E-mail: pietrofrancesco.addeo@chru-strasbourg.fr

How to cite this article: Addeo P. Minimally invasive pancreaticoduodenectomy with venous resection: results of a systematic review. Mini-invasive Surg 2020;4:64. http://dx.doi.org/10.20517/2574-1225.2020.47

Received: 5 May 2020 First Decision: 19 Jun 2020 Revised: 27 Aug 2020 Accepted: 31 Aug 2020 Published: 12 Oct 2020

Academic Editor: Giulio Belli Copy Editor: Cai-Hong Wang Production Editor: Jing Yu

\begin{abstract}
Aim: Growing experience with minimally invasive pancreaticoduodenectomy (PD) has led surgeons to expand the indications for this approach. We systematically reviewed the literature on minimally invasive PD with venous resection.
\end{abstract}

Methods: The EMBASE, MEDLINE, and Cochrane central databases were systematically searched for articles from January 2010 to January 2020 describing cases of PD with venous resection. The search was conducted in accordance with the Preferred Reporting Items for Systematic Reviews and Meta-Analyses guidelines. The primary outcomes were feasibility and conversion rate. Secondary outcomes were morbidity, mortality, blood loss and 1-year survival.

Results: The literature search found 9 studies reporting 140 patients undergoing PD with venous resection. Sixty-six PDs were performed robotically (47.1\%). The conversion rate ranged from 0\% to 55\%, blood loss ranged from 200 to $842 \mathrm{~mL}$, and operative time ranged from 397 to $518 \mathrm{~min}$. There were 82 lateral (58.5\%) and 18 segmental (12.8\%) PDs with venous resection. One patient had an associated arterial resection (0.7\%). A graft was used for venous reconstruction in 28 patients (20\%). Eight deaths (5.7\%) were reported postoperatively.

Conclusion: Minimally invasive pancreatectomies with synchronous lateral venous resections are increasingly reported by highly experienced surgeons in high-volume institutions. Further experience is needed to validate this approach and prove its advantages over open surgery.

\footnotetext{
(c) (i) (๑) The Author(s) 2020. Open Access This article is licensed under a Creative Commons Attribution 4.0 International License (https://creativecommons.org/licenses/by/4.0/), which permits unrestricted use, sharing, adaptation, distribution and reproduction in any medium or format, for any purpose, even commercially, as long as you give appropriate credit to the original author(s) and the source, provide a link to the Creative Commons license, and indicate if changes were made.
}

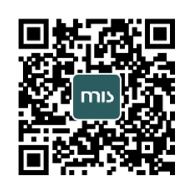


Keywords: Pancreatectomy, vascular resection, venous resection, arterial resection, locally advanced tumours

\section{INTRODUCTION}

Since the first description in 1994 by Gagner and Pomp, minimally invasive (MIS) pancreaticoduodenectomy (PD) has been considered among the most complex abdominal procedures ${ }^{[1]}$. Even if the feasibility and safety of the minimally invasive approach of MIS PD has been demonstrated in several randomized and observational studies, reluctance still exist to embrace MIS for $\mathrm{PD}^{[2-5]}$. PDs are in fact a complex procedure entailing (1) extensive dissection around the mesenteric and coeliac vessels; (2) dissection above and below the mesocolon (multi-quadrant procedure); (3) a long and a technically challenging digestive reconstruction; and (4) inherent morbidity and mortality which seems not reduced by the MIS approach.

For these reasons, the MIS approach to PD is still not widely practised compared with other procedures such as colonic and gastric resection. However, increased experience with laparoscopy and robotics in surgery has allowed pioneer centres to test the feasibility and safety of these approaches for more advanced procedures. In fact, from a theoretical point of view, the magnified view provided by the laparoscope and/ or the $3 \mathrm{D}$ vision achieved by robotics can be of great help during the dissection. This enhanced view, coupled by the superior dexterity of the robotic instruments, can be of great help in complex suturing.

Indeed, complex procedures such as renal or splenic artery aneurysm repair, nephrectomy with caval thrombectomy, and kidney and pancreas transplantation have been described in recent years ${ }^{[6-11]}$. As a result of these developments and the increased experience achieved with MIS PDs, small series of MIS pancreatectomies with vascular resection have been reported ${ }^{[3,5,11-19]}$. The safety and results of this approach remains to be determined. In this article we systematically reviewed the literature on the topic of MIS PD with vascular resection, evaluating the safety and feasibility as well as the outcomes of this approach.

\section{METHODS}

\section{Data selection}

The EMBASE, MEDLINE, and Cochrane central databases were systematically searched for articles from January 1995 to January 2020 describing cases of PD with venous resection. The search was conducted in accordance with the Preferred Reporting Items for Systematic Reviews and Meta-Analyses guidelines, and it was limited to manuscripts written in English. The following were used as search terms: "pancreaticoduodenectomy" combined with "laparoscopic" and/or "robotic" and "vascular resection" and/or "venous resection". Potentially eligible articles were screened, and exclusion criteria included: (1) duplicated articles; (2) articles that were not in English or that described animal studies; and (3) registry studies for whom the patient outcomes could not be precisely detailed. References of selected articles were checked for additional cases. The primary outcomes of the review were feasibility of PD with venous resection. Secondary outcomes were morbidity, mortality, blood loss and 1-year survival. All the data were extracted using a standardized extraction form.

\section{Statistical analysis}

Continuous data are expressed as the mean \pm standard deviation or the median and range as appropriate, whereas categorical variables are presented as numbers and percentages. Differences between groups were assessed by the chi-squared or Fisher's exact test (categorical variables) and the Wilcoxon rank sum test or the student's $t$ test (continuous variables). 


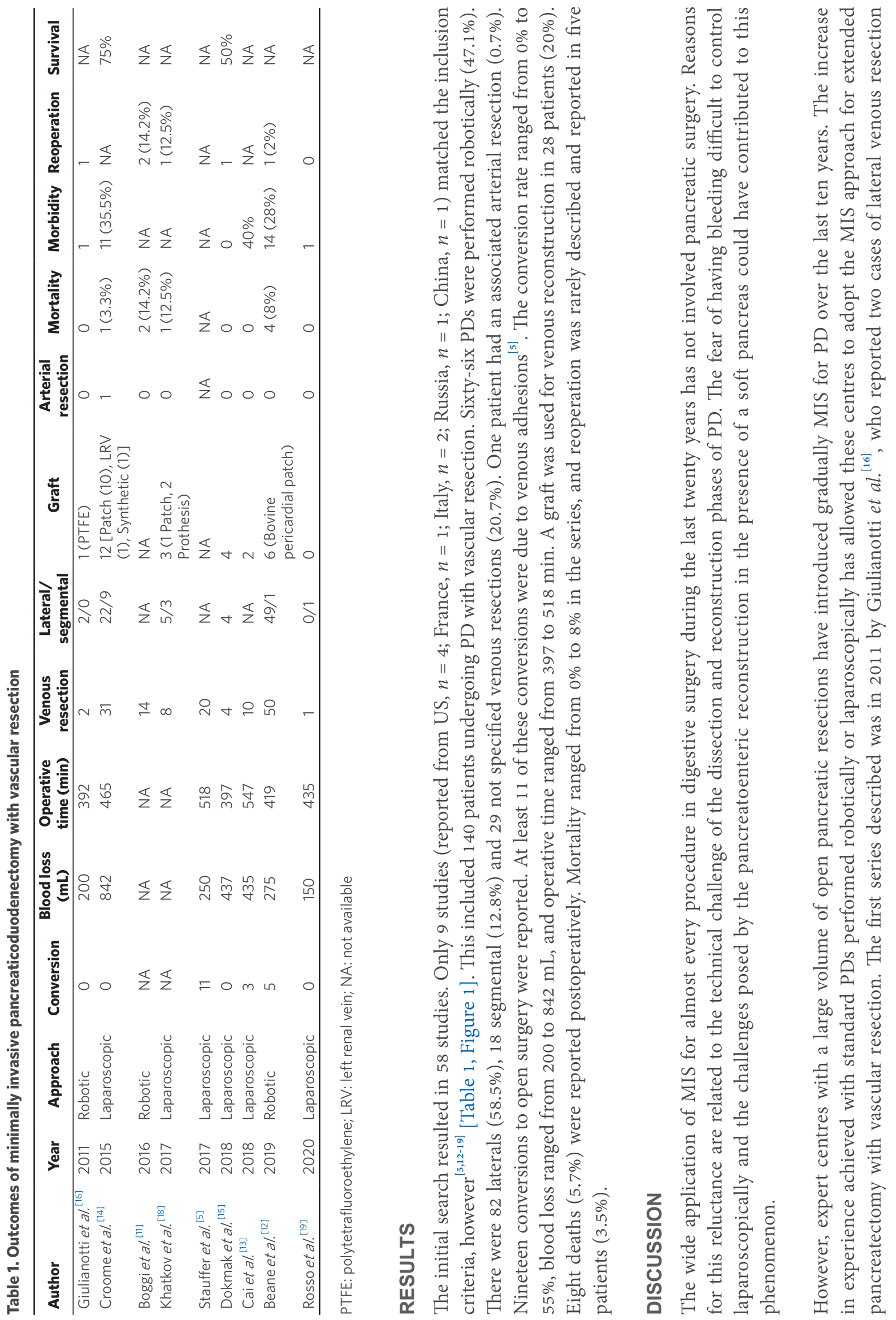




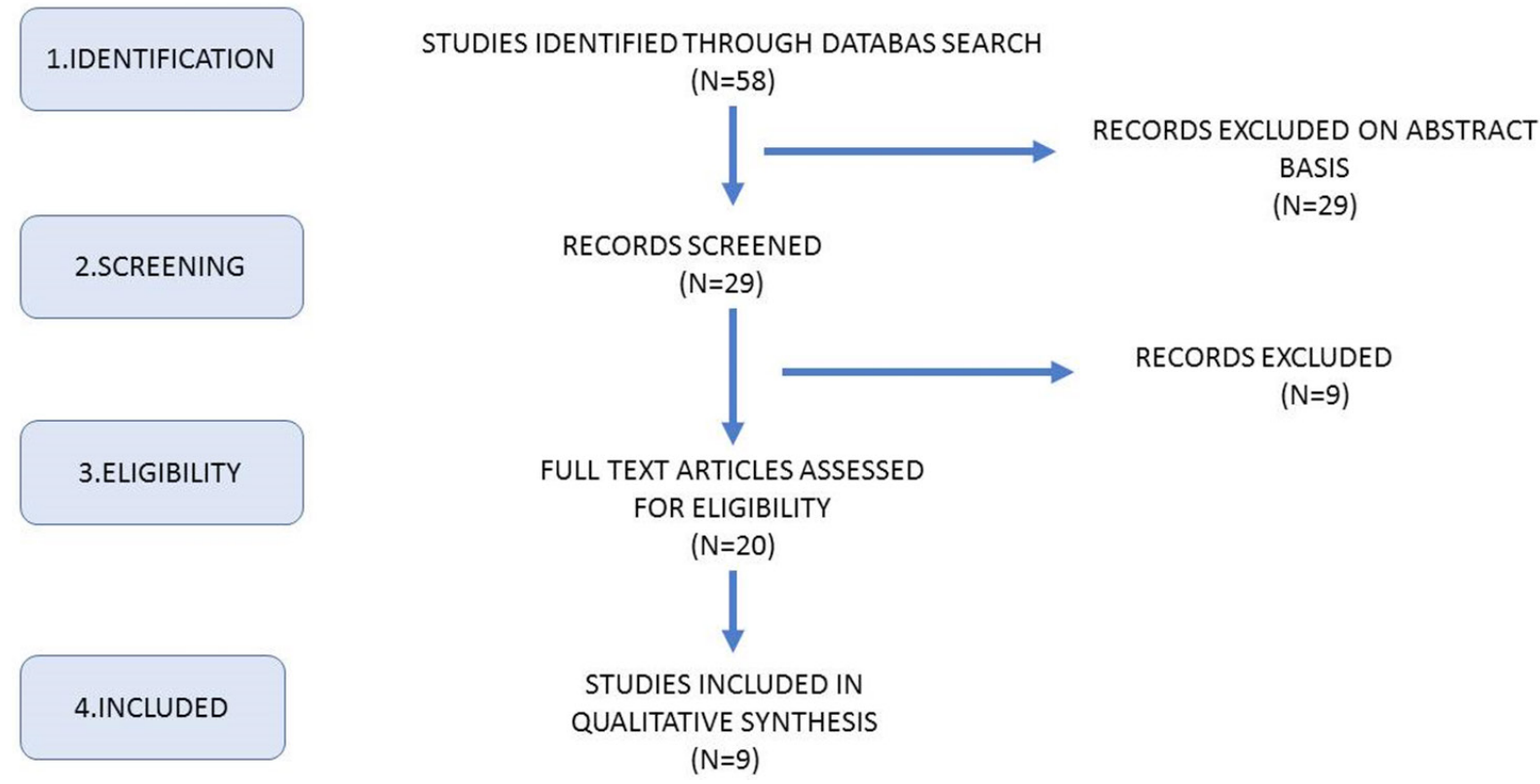

Figure 1. PRISMA flow chart of study selection

during robotic PD. Since then, further studies have reported experience with this approach. This current review found $140 \mathrm{PD}$ with venous resection, of which 50\% were performed robotically.

Most of these minimally invasive PDs with venous resection were lateral resections (58.5\%), which needed either direct suture-repair or patch-interposition. This is certainly related to less advanced cases operated by MIS and to the challenges posed by segmental resection. Segmental resection is, in fact, needed more often in case of long and circumferential venous involvement; can require extensive mesenteric mobilization in order to achieve a tension-free venous approximation; and can require prolonged vascular clamping which can cause bowel oedema impairing the endoscopic view. The largest series to date of robotic PD with venous resection (50 cases) reported only one case of segmental resection ${ }^{[12]}$, whereas Croome et al. ${ }^{[14]}$ reported 9 over 22 cases of laparoscopic segmental venous resection.

Patch-repair was the technique of choice in case of a large defect of the lateral venous wall. Peritoneal, bovine pericardium and polytetrafluoroethylene material were variably used for venous patches. Postoperative thrombosis was rarely reported ${ }^{[3,15,17]}$. We found a $5.7 \%$ postoperative mortality rate which is in the range of that reported in large registry studies in Europe ${ }^{[20,21]}$. The causes of mortality were not different to those in open PD, with no specific complications related to the approach used. Blood loss and operative time seem to be comparable to that reported for open surgery.

In conclusion, despite limited experience, the minimally invasive approach to $\mathrm{PD}$ with venous resection seems feasible, with an acceptable rate of mortality and morbidity in the hands of highly experienced pancreatic surgeons. The advantages of this approach over open surgery remain to be determined.

\section{DECLARATIONS}

\section{Authors' contributions}

The author contributed solely to the article.

\section{Availability of data and materials}

Not applicable. 


\section{Financial support and sponsorship}

None.

\section{Conflicts of interest}

The author declared that there are no conflicts of interest.

\section{Ethical approval and consent to participate}

Not applicable.

\section{Consent for publication}

Not applicable.

\section{Copyright}

(C) The Author(s) 2020

\section{REFERENCES}

1. Gagner M, Pomp A. Laparoscopic pylorus-preserving pancreatoduodenectomy. Surg Endosc 1994;8:408-10.

2. van Hilst J, de Rooij T, Bosscha K, Brinkman DJ, van Dieren S, et al. Laparoscopic versus open pancreatoduodenectomy for pancreatic or periampullary tumours (LEOPARD-2): a multicentre, patient-blinded, randomised controlled phase 2/3 trial. Lancet Gastroenterol Hepatol 2019;4:199-207.

3. Boggi U, Signori S, De Lio N, Perrone VG, Vistoli F, et al. Feasibility of robotic pancreaticoduodenectomy. Br J Surg 2013;100:917-25.

4. Zureikat AH, Beane JD, Zenati MS, Al Abbas AI, Boone BA, et al. 500 Minimally invasive robotic pancreatoduodenectomies: one decade of optimizing performance. Ann Surg 2019; doi: 10.1097/SLA.0000000000003550.

5. Stauffer JA, Coppola A, Villacreses D, Mody K, Johnson E, et al. Laparoscopic versus open pancreaticoduodenectomy for pancreatic adenocarcinoma: long-term results at a single institution. Surg Endosc 2017;31:2233-41.

6. Boggi U, Signori S, Vistoli F, D'Imporzano S, Amorese G, et al. Laparoscopic robot-assisted pancreas transplantation: first world experience. Transplantation 2012;93:201-6.

7. Giulianotti P, Gorodner V, Sbrana F, Tzvetanov I, Jeon H, et al. Robotic transabdominal kidney transplantation in a morbidly obese patient. Am J Transplant 2010;10:1478-82.

8. Giulianotti PC, Bianco FM, Addeo P, Lombardi A, Coratti A, et al. Robot-assisted laparoscopic repair of renal artery aneurysms. J Vasc Surg 2010;51:842-9.

9. Giulianotti PC, Buchs NC, Coratti A, Sbrana F, Lombardi A, et al. Robot-assisted treatment of splenic artery aneurysms. Ann Vasc Surg 2011;25:377-83.

10. Abaza R, Shabsigh A, Castle E, Allaf M, Hu JC, et al. Multi-institutional experience with robotic nephrectomy with inferior vena cava tumor thrombectomy. J Urol 2016;195:865-71.

11. Boggi U, Napoli N, Costa F, Kauffmann EF, Menonna F, et al. Robotic-assisted pancreatic resections. World J Surg 2016;40:2497-506.

12. Beane JD, Zenati M, Hamad A, Hogg ME, Zeh HJ, et al. Robotic pancreatoduodenectomy with vascular resection: outcomes and learning curve. Surgery 2019;166:8-14.

13. Cai Y, Gao P, Li Y, Wang X, Peng B. Laparoscopic pancreaticoduodenectomy with major venous resection and reconstruction: anterior superior mesenteric artery first approach. Surg Endosc 2018;32:4209-15.

14. Croome KP, Farnell MB, Que FG, Reid-Lombardo KM, Truty MJ, et al. Pancreaticoduodenectomy with major vascular resection: a comparison of laparoscopic versus open approaches. J Gastrointest Surg 2015;19:189-94; discussion 194.

15. Dokmak S, Aussilhou B, Calmels M, Maghrebi H, Ftériche FS, et al. Laparoscopic pancreaticoduodenectomy with reconstruction of the mesentericoportal vein with the parietal peritoneum and the falciform ligament. Surg Endosc 2018;32:3256-61.

16. Giulianotti PC, Addeo P, Buchs NC, Ayloo SM, Bianco FM. Robotic extended pancreatectomy with vascular resection for locally advanced pancreatic tumors. Pancreas 2011;40:1264-70.

17. Kendrick ML, Sclabas GM. Major venous resection during total laparoscopic pancreaticoduodenectomy. HPB (Oxford) 2011;13:454-8.

18. Khatkov IE, Izrailov RE, Khisamov AA, Tyutyunnik PS, Fingerhut A. Superior mesenteric-portal vein resection during laparoscopic pancreatoduodenectomy. Surg Endosc 2017;31:1488-95.

19. Rosso E, Zimmitti G, Iannelli A, Garatti M. The 'TRIANGLE Operation' by laparoscopy: radical pancreaticoduodenectomy with major vascular resection for borderline resectable pancreatic head cancer. Ann Surg Oncol 2020;27:1613-4.

20. Farges O, Bendersky N, Truant S, Delpero JR, Pruvot FR, et al. The theory and practice of pancreatic surgery in France. Ann Surg 2017;266:797-804.

21. Nimptsch U, Krautz C, Weber GF, Mansky T, Grutzmann R. Nationwide in-hospital mortality following pancreatic surgery in Germany is higher than anticipated. Ann Surg 2016;264:1082-90. 